\title{
Depression and glycemic control in a sample of patients with type 2 diabetes
}

\begin{abstract}
Background: Diabetes mellitus is a serious public health burden, accounting for substantial morbidity, disability, mortality, and health care cost; in addition to impaired physical health. Patients with diabetes frequently have comorbid affective illness; they are twice likely to be depressed as people without chronic diseases. Depression may be a risk factor for poor metabolic control in diabetes, however some investigators have found moderate to strong association between depression and glycemic control, although others have found no relationship.
\end{abstract}

Purpose of the study: The purpose of this study was to investigate the association of comorbid depression and glycemic control in a clinical sample of adult Saudi patients with type 2 diabetes.

Methods: The sample included 172 type 2 diabetes mellitus adult patients regularly followed in diabetes clinic at Saudi airlines medical center in Jeddah, western Saudi Arabia. We assessed depression by beck depression inventory II (BDI-II), and clinical diagnosis according to DSM IV TR by an expert psychiatrist, and assessed diabetic control by hemoglobin A1c (HbA1c), and fasting blood glucose (FBG). The association between depression and diabetic control was analyzed cross-sectionally, and controlled for demographics (age, sex, employment, education), and clinical variables (smoking, BMI, duration of DM, diabetes medications, medical comorbidities, lipid profile, and renal functions). We used student t-test for group comparison, X2 for baseline association between categorical baseline variables, one-way analyses of variant (ANOVA), Pearson correlation coefficient to examine univariate associations between continuous baseline variables, and multiple regression analyses to adjust for the demographic and clinical potentially confounding factors.

Results: Unadjusted analyses revealed a significant positive relationship between BDI scores and $\mathrm{HbA} 1 \mathrm{c}(\mathrm{r}=0.17, \mathrm{p}=0.02)$, this relationship was evident throughout the entire range of BDI scores. Also the comparison between clinically depressed and nondepressed groups of patients using t-test revealed that $\mathrm{HbAl} \mathrm{c}$ is significantly higher in the depressed group with $\mathrm{P}$ value (0.01). After adjustment for demographic variables, BDI scores, and clinical depression remained associated with HbAlc changes, but after full adjustment for all demographic and clinical variables, fully adjusted analyses revealed that duration of diabetic illness is the strongest factor which predicts higher $\mathrm{HbA} 1 \mathrm{c}(\mathrm{p}=0.00)$, and only clinically diagnosed major depressive disorder (MDD), and probable severe depression (BDI score $>25$ ), - but not the entire range of BDI scoreswas less significant predictors of higher $\mathrm{HbA} 1 \mathrm{c}[\mathrm{P}=(0.034)$ and $(0.046)$ respectively].

Conclusion: patients with diabetes and comorbid sever depressive symptomatology or clinical major depressive disorders are associated with poor glycemic control in type 2 diabetes. However, to study the persistence of this relation prospectively, to explore the factors that could mediate this relation, as well as the study of impact of treating depression on glycemic control may be an interesting areas for further research.

Keywords: depression, MDD, depressive disorder, diabetes, diabetic control, HbA1c
Volume 3 Issue 5 - 2017

\author{
Hesham Abuhegazy,' Heba Elkeshishi, ${ }^{2}$ \\ Hesham Farrag, ${ }^{3}$ Noha Saleh ${ }^{4}$ \\ 'Al-Azhar University faculty of medicine, Department of \\ psychiatry and behavioral sciences, Egypt \\ ${ }^{2}$ El-menia University faculty of arts, Department of psychology, \\ Egypt \\ ${ }^{3}$ Zagazig University faculty of medicine, Department of internal \\ medicine, Egypt \\ ${ }^{4}$ Alexendia University institute of public health, Biostatistics \\ department, Egypt
}

\begin{abstract}
Correspondence: Hesham Abuhegazy,Al-Azhar University faculty of medicine, Department of psychiatry and behavioral sciences, Cairo, Egypt, Tel 966530107236 , Email abuhegazy@gmail.com
\end{abstract}

Received: April 3, 2017 | Published: June 21, 2017
Abbreviations: $\mathrm{HbA}_{1} \mathrm{c}$, hemoglobin $\mathrm{A}_{1} \mathrm{c}$; BDI-II, beck depression inventory ii; FBG, fasting blood glucose; DM, diabetes mellitus; BMI, body mass index; DSMIV, diagnostic and statistical manual of mental disorders; ECG, electro cardio gram; LDL, low density lipoprotein

\section{Introduction}

Diabetes mellitus is a serious public health burden, accounting for substantial morbidity, disability, mortality, and health care cost. ${ }^{1}$ Evidence from large randomized clinical trials indicates that good glycemic control as evidenced by low hemoglobin $\mathrm{A}_{1} \mathrm{c}\left(\mathrm{HbA}_{1} \mathrm{c}\right)$ scores, is associated with decreased complications, decreased mortality, and improved quality of life. ${ }^{2}$ People with diabetes are twice likely to be depressed as people without chronic diseases. ${ }^{3}$ Current epidemiological evidence suggests that at least one third of adults with diabetes suffer from clinically relevant depressive disorders. ${ }^{4-6}$ Comorbid depression in adults with diabetes is associated with higher complication rates, increased health care use and cost, diminished quality of life, increased disability, and increased risk of death, ${ }^{2}$ as well depression may be a risk factor for poor metabolic control in diabetes, however some investigators have found moderate 
to strong association between depression and glycemic control, although others have found no relationship. ${ }^{7}$ The lack of reporting of sociodemographic and clinical variables in most studies is a significant limitation, as analyses of the association between depression and diabetes severity and $\mathrm{HbA}_{1} \mathrm{c}$ have often not controlled for potentially important confounding variables. ${ }^{8}$ The purpose of this study was to investigate the association of comorbid depression and glycemic control after controlling for demographic and clinical characteristics.

\section{Methods}

\section{Patients}

The adult patients (18-65 years old) diagnosed with type-2 diabetes and regularly followed through the outpatient diabetes clinic in Saudi Arabian airline medical center in Jeddah, Saudi Arabia were asked to participate in the study, with assuming that effect size is $0.3,{ }^{4-6}$ alpha error 5\%, and power $80 \%$, the sample size should be not less than 143 ( according to $G$ power 3.1.3), we approached 224 patients, only 21 of them refused participation, while all others accepted to participate and gave informed consent., persons who declined participation, and participants were not significantly different in terms of age, and sex. Out of potential participants, 31 patients were excluded because they fulfill one or more of the following exclusion criteria:

a. Type of diabetes is indeterminate from the medical records and/or consultation with the physician

b. There is History of stroke, brain surgery, closed head injury, dementia, pregnancy, or illness that could affect glucose control.

c. They are unable to independently complete BDI questionnaire (Arabic version) because of visual disability or primary language other than Arabic.

Participants who included were male and female patients between ages of 18- 65 years with definite diagnoses of type- 2 diabetes mellitus.

\section{Measures}

Depressive symptoms were assessed by use of Arabic version of beck depression inventory II (the psychological corporation, Orlando, FL). BDI-II has been shown to have high reliability and validity, ${ }^{9}$ furthermore BDI has been validated as a tool for measuring depression in diabetic patients, it is also widely used to assess depression in both community, and clinical samples. ${ }^{10-12}$ BDI has been translated into Arabic by Ahmed Abdelkhalek and shown high reliability and validity as well. Scores of 16 and above were used as a cut off point for probable depression, and 25 and above for confirmed depression. ${ }^{13}$ Clinical depression has been assessed by direct interview performed by a consultant psychiatrist, with proper experience, and patients been diagnosed according to DSMIV-TR classification. Glycemic control was assessed by both fasting blood glucose, and $\mathrm{HBA}_{1} \mathrm{c}$, an accepted index of average glucose level over the previous 12-16 weeks.

\section{Procedures}

After informed consent, patients who included in the study were interviewed to collect personal and demographic information patients were asked to complete the BDI-II in the interview. All patients undergoes an interview with the diabetes physician where vital signs including pulse, temperature, blood pressure, height, weight, BME, have been assessed, all data about his/her illness were reviewed and completed including duration of diabetes, types of medications, periods of refill, as well physician assessed the presence of hypoglycemic, or hyperglycemic symptoms, diabetic complications, medical comorbidities, recent infections, other medical conditions, or medications which may affect glucose control.

All patients undergoes ECG, and echocardiogram to assess ejection fraction and left ventricular hypertrophy, fundus examination to assess retinopathy, and full laboratory make up (either obtained from medical records if performed within 3 months, or newly requested) including fasting blood glucose, HBA1c, serum creatinin and urea, 24 hours protein, and full lipid profile. All patients have interviewed by consultant psychiatrist, history of psychiatric illnesses and psychotropic medications was taken, mental state examination, and diagnosis according to DSMIV-TR was performed, (the psychiatrist was unaware about the BDI scores). Proper action was done for all patients found having clinical depression, or other psychiatric morbidities. All procedures were approved by the research and ethics committee of Saudi airlines medical center.

\section{Statistical analysis}

Data were analyzed using the software SPSS 16.0 for Windows (SPSS Inc, Chicago, Ill). Firstly, the data were tested for normal distribution using Kolmogrov and Smirnov test. We used Twotailed $t$-tests or $\mathrm{x}^{2}$ tests to examine difference between patients with depression and those without depression regarding sociodemographic, and clinical variables. Pearson's correlation, ANOVA and $t$-tests were used to determine significant associations between the possible covariates, BDI score and $\mathrm{HbA}_{1} \mathrm{c}$. Statistical significance was declared for $\mathrm{p} \leq 0.05$. To detect the significant predictors of $\mathrm{HbA}_{1} \mathrm{c}$ all the significantly associated variables in univariate analysis were included in multiple hierarchical regression models.

Prior to conducting a hierarchical multiple regressions, the relevant assumptions of this statistical analysis were tested. Firstly, an examination of correlations revealed that no independent variables were highly correlated except for cholesterol level and LDL. Also, the collinearity statistics (i.e., Tolerance and VIF) for both variables were high beyond the accepted limits. So cholesterol and LDL were excluded from the regression model. Correction was done for multiple testing through a three stage hierarchical multiple regression conducted with $\mathrm{HbA}_{1} \mathrm{C}$ as the dependent variable. Sociodemographic variables (sex and education) was entered at stage one of the regression to control for their effect. The clinical variables were entered at stage two, and finally depression variables (Clinical diagnosis and BDI score) were entered at stage three as dummy variables.

\section{Results}

\section{Patients' characteristics}

Out of 224 eligible patients approached, 203 approved to participate, and only 172 patients were enrolled. The study sample comprised of 172 type 2 diabetic patients, $69.8 \%$ of them were males, mean age was $51.3(\mathrm{SD}=6.2)$ years, the majority had intermediate education $(60.9 \%)$, more than half were employed (51.2\%) and $42.4 \%$ of them were smokers, $93 \%$ were receiving oral diabetic medications, Regarding their clinical assessment data, mean BMI was $31.9(\mathrm{SD}=5.8)$, mean duration of diabetes was $10.7(\mathrm{SD}=3.5)$ years, mean FBS was 176.9 $(\mathrm{SD}=7.4)$ and mean $\mathrm{HbA}_{1} \mathrm{C}$ was $8.7(\mathrm{SD}=2$. and ranged from 5.5 to 14.8) (Table 1). BDI score ranged from 0 to 43 with a mean of 14.8 $(\mathrm{SD}=8.9)$, depression was evidenced in $46.5 \%$ of the patients; with $16.3 \%$ of the patients were diagnosed with MDD while $30.3 \%$ were diagnosed with other depressive disorders. $14 \%$ receiving multiple antidepressants and 14\% had psychiatric co-morbidity (Table 2). 
Table I Descriptive statistics of the study sample according to DSMIV diagnosiss

\begin{tabular}{|c|c|c|c|c|}
\hline Characteristics & All sample $N=\mid 72$ & Not depressed $\mathrm{N}=92$ & Depressed $\mathbf{N}=\mathbf{8 0}$ & $P$ value \\
\hline Mean Age in Years $\pm S D$ & $51.3 \pm 6.2$ & $51.7 \pm 6.4$ & $51.8 \pm 5.8$ & 0.323 \\
\hline Mean BMI $\pm S D$ & $31.9 \pm 5.8$ & $31.5 \pm 5.3$ & $31.7 \pm 6.6$ & 0.907 \\
\hline Mean Duration of Diabetes \pm SD & $10.7 \pm 3.5$ & $10.7 \pm 8.1$ & $10.9 \pm 7.4$ & 0.926 \\
\hline Mean FBS $\pm S D$ & $176.9 \pm 7.4$ & $162.1 \pm 5.4$ & $200.3 \pm 6.8$ & $0.000 *$ \\
\hline Mean $\mathrm{HbAIC} \pm \mathrm{SD}$ & $8.7 \pm 2.1$ & $8.4 \pm 2.2$ & $9.1 \pm 2.1$ & $0.010^{*}$ \\
\hline Mean Cholesterol $\pm S D$ & $|7| . \mid \pm 46.3$ & $166.5 \pm 43.2$ & $176.5 \pm 43.1$ & 0.169 \\
\hline Mean Triglyceride $\pm S D$ & $|4| . \mid \pm 86.9$ & $131.9 \pm 67.5$ & $153.9 \pm 74.9$ & $0.004 *$ \\
\hline Mean HDL $\pm S D$ & $48.5 \pm 15.2$ & $47.96 \pm 13.9$ & $48.9 \pm 15.2$ & 0.698 \\
\hline Mean LDL $\pm S D$ & $99.6 \pm 38.4$ & $91.5 \pm 35.5$ & $102.6 \pm 39.8$ & 0.105 \\
\hline Mean Serum Creatinine $\pm S D$ & $1.9 \pm 0.9$ & $1.01 \pm 0.30$ & $0.90 \pm 0.19$ & $0.005^{*}$ \\
\hline Mean Serum Urea $\pm S D$ & $14.9 \pm 4.1$ & $15.3 \pm 4.9$ & $14.4 \pm 2.5$ & 0.158 \\
\hline Mean Protein Creatinine Ratio $\pm S D$ & $0.86 \pm 0.5$ & I.I \pm 0.7 & $0.34 \pm 0.3$ & $0.002 *$ \\
\hline \multicolumn{5}{|l|}{ Gender (\%) } \\
\hline Male & $120(69.8)$ & $72(78.3)$ & $48(60.0)$ & $0.009 *$ \\
\hline Female & $52(30.2)$ & $20(21.7)$ & $32(40.0)$ & \\
\hline \multicolumn{5}{|l|}{ Level of Education (\%) } \\
\hline Illiterate & $4(2.6)$ & $4(4.3)$ & $0(0)$ & \\
\hline Read and Write & $12(7.9)$ & $0(0)$ & $12(15.0)$ & \\
\hline Intermediate & $112(60.9)$ & $56(60.9)$ & $56(70.0)$ & $0.000^{*}$ \\
\hline High & $44(28.5)$ & $32(34.8)$ & $12(15.0)$ & \\
\hline \multicolumn{5}{|l|}{ Employment (\%) } \\
\hline Non & $84(48.8)$ & $48(52.2)$ & $36(45.0)$ & 0.348 \\
\hline Employed & $88(5 \mid .2)$ & $44(47.8)$ & $44(55.0)$ & \\
\hline \multicolumn{5}{|l|}{ Smoking (\%) } \\
\hline No & $87(57.6)$ & $52(56.5)$ & $40(50.0)$ & 0.392 \\
\hline Yes & $64(42.4)$ & $40(43.5)$ & $40(50.0)$ & \\
\hline \multicolumn{5}{|l|}{ Medication for Diabetes (\%) } \\
\hline Insulin & $12(7.0)$ & $4(4.3)$ & $8(10.0)$ & 0.147 \\
\hline Oral & $160(93.0)$ & $88(95.7)$ & $72(70.0)$ & \\
\hline \multicolumn{5}{|l|}{ Ejection Fraction (\%) } \\
\hline $50 \%$ and More & $160(93.0)$ & $88(95.7)$ & $72(90.0)$ & 0.147 \\
\hline Less than $50 \%$ & $12(7.0)$ & $4(4.3)$ & $8(10.0)$ & \\
\hline
\end{tabular}

*Significant $\mathrm{P}$ value of $\mathrm{x} 2$ or $\mathrm{t}$-test $\leq 0.05$

\section{Factors associated with depression}

The comparison between clinically depressed diabetic patients and non depressed ones (Table 1) revealed that depressed patients were more females $(\mathrm{p}=0.009)$, less educated $(\mathrm{p}=0.000)$, with higher fasting blood glucose $(\mathrm{p}=0.000), \mathrm{HbA}_{1} \mathrm{c}(\mathrm{p}=0.010)$, and triglycerides $(\mathrm{p}=0.006)$. Patients reporting high BDI score (more depressive symptoms) - as shown in table 3 - were mostly females $(\mathrm{P}=0.006)$, less educated $(\mathrm{P}=0.021)$, with higher fasting blood sugar $(\mathrm{r}=0.327$, $\mathrm{P}=0.000)$, cholesterol $(\mathrm{r}=0.328, \mathrm{P}=0.000)$, and LDL $(\mathrm{r}=0.340$, $\mathrm{P}=0.000)$, they were more insulin users $(\mathrm{P}=0.000)$, had a longer duration of psychiatric illness $(\mathrm{r}=0.258, \mathrm{P}=0.000)$, more psychiatric co morbidity $(\mathrm{P}=0.000)$, and they were using multiple antidepressants
$(\mathrm{P}=0.000)$.

\section{Factors associated with glycemic control}

Patients with poor glycemic control (higher $\mathrm{HbA}_{1} \mathrm{c}$ ) were mostly females $(\mathrm{p}=0.000)$, less educated $(\mathrm{P}=0.012)$, had more hyperglycemic, less hypoglycemic symptoms $(\mathrm{p}=0.000$, and 0.001$)$, less medical co morbidities $(\mathrm{p}=0.003)$, poorer ejection fraction $(\mathrm{p}=0.000)$, longer duration of diabetes $(\mathrm{p}=0.000)$, longer duration of psychiatric illness $(\mathrm{p}=0.025)$, and higher levels of laboratory investigations (FBS, cholesterol, triglycerides, LDL and serum urea). Some covariates are correlated with both BDI score and $\mathrm{HbA}_{1} \mathrm{c}$ as sex, education, FBS, cholesterol, LDL /and duration of psychiatric illness (Table 3) 
Table 2 Psychological assessment of study sample

\begin{tabular}{ll}
\hline \multicolumn{2}{l}{ Psychiatric diagnosis (\%) } \\
\hline Not Depressed & $92(53.3)$ \\
Depressed & $80(46.5)$ \\
MDD & $28(16.3)$ \\
Mixed Depression and Anxiety & $12(6.9)$ \\
Dysthymia & $40(23.3)$ \\
\hline Psychotropic medication (\%) & \\
\hline Non & $132(76.7)$ \\
One Drug & $16(9.3)$ \\
Multiple Drugs & $24(14.0)$ \\
\hline Psychiatric co-morbidity (\%) & $148(86.0)$ \\
\hline Non & $24(14.0)$ \\
\hline
\end{tabular}

Unadjusted correlation between depression and glycemic control: Showed that there was a significant linear correlation between BDI scores and $\mathrm{HbA}_{1} \mathrm{C}(\mathrm{r}=0.173, \mathrm{P}=0.021)$, and between $\mathrm{BDI}$ scores and fasting blood sugar $(\mathrm{r}=0.327, \mathrm{p}=0.000)$ indicating that depression is associated with poor glycemic control. The scatter plot in (Figures 1 Table 3 Factors associated with BDI score and HBAIc
\& 2) showed a linear relationship between them.

\section{Predictors of glycemic control}

The hierarchical multiple regression (Table 4) revealed that Sociodemographic factors contributed significantly to the regression model, $(F=8.4, p=0.000)$ and accounted for $8 \%$ of the variation in $\mathrm{HbA}_{1} \mathrm{c}$. Adding the clinical variables to the model explained an additional $65.5 \%$ of variation in $\mathrm{HbA}_{1} \mathrm{c}$ and this change in $R^{2}$ was significant, $(F=28.07, p=0.000)$. Finally, the addition of clinical depression and BDI score to the regression model both explained an additional $67.8 \%$ of the variation in $\mathrm{HbA}_{1} \mathrm{c}$ and this change in $R^{2}$ square was also significant, $(F=22.2, p=0.000)$. When all independent variables were included in stage three of the regression model, clinically diagnosed major depressive disorder (MDD) - but not other depressive diagnoses $(\mathrm{p}=0.034)$-, and probable severe depression (BDI score $>25)$, - but not the entire range of BDI scores- $(p=0.046)$ was significant predictors of higher $\mathrm{HbA}$ c.other predictors of $\mathrm{HbA}_{1} \mathrm{c}$ were duration of diabetes which was the most important predictor of $\mathrm{HbA}_{1} \mathrm{c}(\mathrm{B}=0.52, \mathrm{p}=0.000)$, hyperglycemic symptoms $(\mathrm{B}=0.20$, $\mathrm{p}=0.000)$, abnormal ejection fraction $(\mathrm{B}=0.27, \mathrm{p}=0.000)$, and higher fasting blood sugar $(B=0.20, p=0.014)$ were also significant predictors of higher HBA c. (Table 4) Illustrated data about the actual relation between depressive symptoms and $\mathrm{HbA}_{1} \mathrm{c}$ where all other covariates were controlled.

\begin{tabular}{|c|c|c|c|c|}
\hline Factors & BDI Score & & $\mathrm{HbA}_{1} \mathrm{c}$ & \\
\hline & Correlation coefficient & $P$ value & Correlation coefficient & $P$ value \\
\hline Age & $r=-0.143$ & 0.056 & $r=-0.001$ & 0.991 \\
\hline BMI & $r=0.103$ & 0.17 & $r=-0.014$ & 0.854 \\
\hline Duration of Diabetes & $r=0.164$ & 0.104 & $r=0.368$ & $0.000 *$ \\
\hline Duration of Psychiatric Illness & $r=0.258$ & $0.000 *$ & $r=0.167$ & $0.025 *$ \\
\hline FBS & $r=0.327$ & $0.000^{*}$ & $r=0.674$ & $0.000^{*}$ \\
\hline Cholesterol & $r=0.328$ & $0.000^{*}$ & $r=0.236$ & $0.001 *$ \\
\hline Triglyceride & $r=0.079$ & 0.294 & $r=0.335$ & $0.000 *$ \\
\hline HDL & $r=-0.025$ & 0.734 & $r=-0.142$ & 0.057 \\
\hline LDL & $r=0.340$ & $0.000 *$ & $r=0.331$ & $0.000 *$ \\
\hline Serum Creatinnine & $r=-0.013$ & 0.866 & $r=0.021$ & 0.785 \\
\hline Serum Urea & $r=0.064$ & 0.393 & $r=0.183$ & $0.014 *$ \\
\hline \multirow[t]{2}{*}{ Protein Creatinine Ratio } & $r=-0.025$ & 0.74 & $r=0.120$ & 0.109 \\
\hline & Mean $\pm S D$ & PValue & Mean $\pm S D$ & P Value \\
\hline \multicolumn{5}{|l|}{ Gender } \\
\hline Male & $13.7 \pm 8.8$ & $0.006^{*}$ & $7.8 \pm 1.7$ & $0.000 *$ \\
\hline Female & $17.7 \pm 8.6$ & & $9.10 \pm 2.1$ & \\
\hline \multicolumn{5}{|l|}{ Level of education } \\
\hline Illiterate & $14.8 \pm 6.8$ & & $9.1 \pm 1.7$ & \\
\hline Read and Write & $22.0 \pm 6.7$ & & $8.9 \pm 1.9$ & \\
\hline Intermediate & $13.7 \pm 8.5$ & $0.012^{*}$ & $8.4 \pm 2.3$ & $0.012 *$ \\
\hline High & $8.0 \pm 0.05$ & & $5.5 \pm 0.5$ & \\
\hline \multicolumn{5}{|l|}{ Employment } \\
\hline Non & $|4.| \pm 7 . \mid$ & 0.253 & $8.7 \pm 2.3$ & 0.898 \\
\hline Employed & $15.5 \pm 10.3$ & & $8.8 \pm 1.8$ & \\
\hline
\end{tabular}


Table Continued...

\begin{tabular}{|c|c|c|c|c|}
\hline \multirow[t]{2}{*}{ Factors } & \multicolumn{2}{|l|}{ BDI Score } & \multicolumn{2}{|l|}{$\mathrm{Hb}_{1} \mathbf{c}$} \\
\hline & Correlation coefficient & $P$ value & Correlation coefficient & $P$ value \\
\hline \multicolumn{5}{|l|}{ Smoking } \\
\hline No & $15.2 \pm 8.9$ & 0.467 & $8.5 \pm 2.1$ & 0.083 \\
\hline Yes & $14.3 \pm 9.1$ & & $9.1 \pm 2.2$ & \\
\hline Insulin & $20.1 \pm 1.5$ & $0.000 *$ & $8.4 \pm 1.8$ & 0.562 \\
\hline Oral & $|4.5 \pm 9|$. & & $8.8 \pm 2.1$ & \\
\hline \multicolumn{5}{|c|}{ Hyperglycemic symptoms } \\
\hline No & $\mid 4.3 \pm 9.1$ & 0.254 & $7.7 \pm 1.3$ & $0.000 *$ \\
\hline \multicolumn{5}{|c|}{ Hypoglycemic symptoms } \\
\hline No & $14.1 \pm 9.5$ & 0.056 & $9.02 \pm 2.1$ & $0.00 I^{*}$ \\
\hline Yes & $15.8 \pm 9.5$ & & $8.04 \pm 1.6$ & \\
\hline \multicolumn{5}{|l|}{ Hypertension } \\
\hline No & $13.8 \pm 5.9$ & 0.08 & $8.8 \pm 2.1$ & 0.611 \\
\hline Yes & $16.2 \pm 1.8$ & & $8.6 \pm 1.9$ & \\
\hline \multicolumn{5}{|l|}{ Co-morbidity } \\
\hline No & $15.2 \pm 9.4$ & 0.684 & $8.9 \pm 2.2$ & $0.003^{*}$ \\
\hline No & $14.2 \pm 9.3$ & $0.000 *$ & $8.7 \pm 1.9$ & 0.699 \\
\hline Yes & $19.0 \pm 4.5$ & & $8.9 \pm 2.9$ & \\
\hline \multicolumn{5}{|c|}{ Antidepressant medications } \\
\hline No* & $13.2 \pm 4.8$ & $0.000 *$ & $8.6 \pm 2.4$ & 0.129 \\
\hline One Drug & $19.5 \pm 5.7$ & & $8.4 \pm 1.6$ & \\
\hline Multiple Drug & $21.2 \pm 9.8$ & & $8.7 \pm 2.03$ & \\
\hline
\end{tabular}

*Significant $\mathrm{P}$ value of pearson correlation coefficient or t-test or ANOVA test $\leq 0.05$

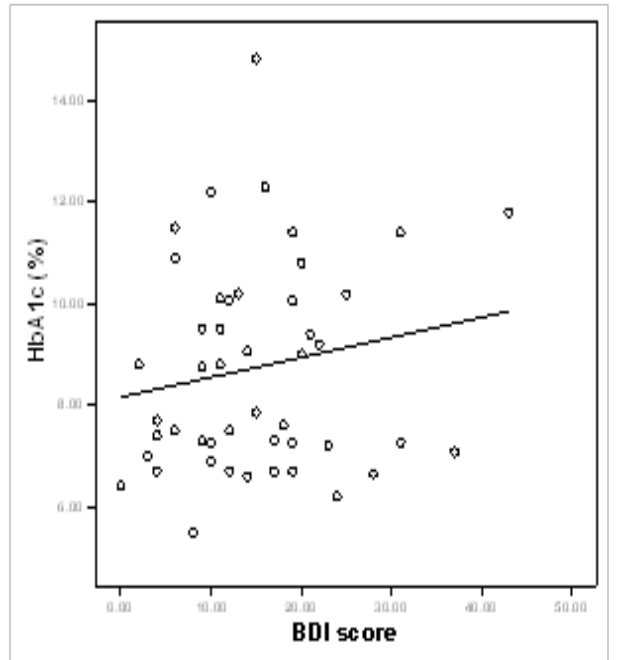

Figure I Relationship of BDI scores and HAIc.

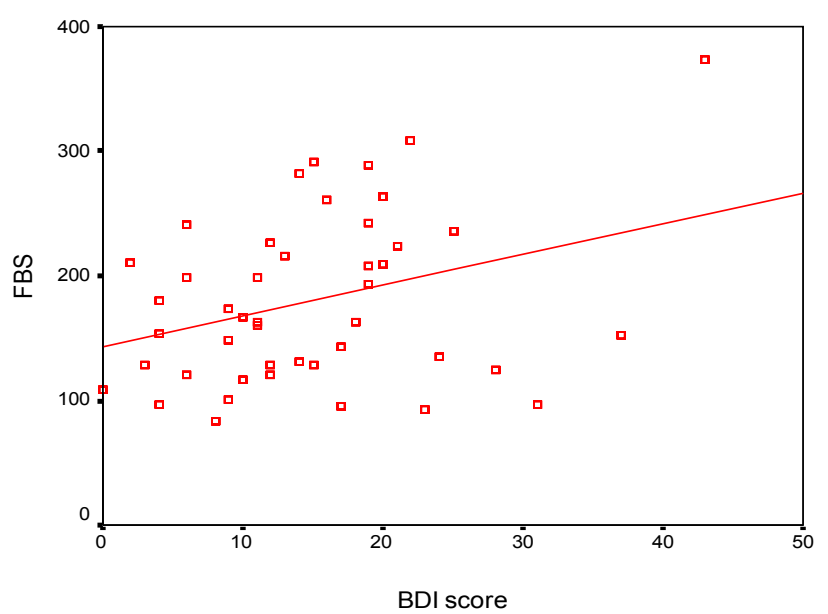

Figure 2 Relationship of BDI scores and fasting blood sugar. 
Table 4 Hierarchical Regression Analysis for Variables predicting $\mathrm{HbA}_{1} \mathrm{c}$

\begin{tabular}{|c|c|c|c|c|c|c|}
\hline Variable & $\beta$ & $\mathbf{t}$ & P-Value & $\mathbf{R}$ & $\mathbf{R}^{2}$ & Adjusted $\mathbf{R}^{2}$ \\
\hline Stepl & & & & 0.302 & 0.091 & 0.08 \\
\hline \multicolumn{7}{|l|}{ Socio-demographic } \\
\hline Education & -0.05 & 0.68 & 0.492 & & & \\
\hline Gender & 0.31 & 4.01 & $0.000 *$ & & & \\
\hline Step 2 & & & & 0.824 & 0.679 & 0.655 \\
\hline \multicolumn{7}{|l|}{ Socio-demographic } \\
\hline Education & -0.07 & 1.03 & 0.185 & & & \\
\hline Gender & 0.06 & 0.797 & 0.427 & & & \\
\hline \multicolumn{7}{|l|}{ Clinical parameters } \\
\hline Duration of Diabetes & 0.42 & 5.6 & $0.000 *$ & & & \\
\hline Duration of Depression & 0.04 & $0.8 \mathrm{I}$ & 0.417 & & & \\
\hline Hyperglycemic Symptoms & 0.3 & 4. 1 & $0.000 *$ & & & \\
\hline Hypoglycemic Symptoms & 0.05 & 1.07 & 0.283 & & & \\
\hline Left Ventricular Hypertrophy & 0.01 & 0.124 & 0.901 & & & \\
\hline Ejection Fraction & 0.24 & 4.2 & $0.000 *$ & & & \\
\hline Co-morbidity & 0.01 & 0.223 & 0.824 & & & \\
\hline Fasting Blood Sugar & 0.16 & 2.09 & $0.004 *$ & & & \\
\hline Triglyceride & 0.06 & 1.2 & 0.215 & & & \\
\hline Serum Urea & 0.05 & 0.9 & 0.365 & & & \\
\hline Step 3 & & & & 0.843 & 0.71 & 0.678 \\
\hline \multicolumn{7}{|l|}{ Socio-demographic } \\
\hline Education & 0.08 & 1.5 & 0.121 & & & \\
\hline Gender & 0.13 & 1.6 & 0.099 & & & \\
\hline \multicolumn{7}{|l|}{ Clinical parameters } \\
\hline Duration of Diabetes & 0.52 & 6.5 & $0.000 *$ & & & \\
\hline Psychological Duration & 0.14 & 1.9 & 0.051 & & & \\
\hline Hyperglycemic Symptoms & 0.2 & 3.6 & $0.000^{*}$ & & & \\
\hline Hypoglycemic Symptoms & 0.07 & 1.3 & 0.189 & & & \\
\hline Left ventricular Hypertrophy & 0.1 & 1.1 & 0.264 & & & \\
\hline Ejection fraction & 0.27 & 4.8 & $0.000 *$ & & & \\
\hline Co-morbidity & 0.05 & 0.91 & 0.362 & & & \\
\hline Fasting Blood Sugar & 0.2 & 2.5 & $0.014^{*}$ & & & \\
\hline Triglyceride & 0.003 & 0.57 & 0.955 & & & \\
\hline Serum Urea & 0.04 & 0.64 & 0.521 & & & \\
\hline \multicolumn{7}{|l|}{ Clinical depression } \\
\hline Mixed Anx \& Dep & 0.01 & 0.26 & 0.789 & & & \\
\hline Dysthymia & 0.03 & 0.36 & 0.178 & & & \\
\hline MDD & 0.15 & 2.1 & $0.034 *$ & & & \\
\hline \multicolumn{7}{|l|}{ BDI score } \\
\hline BDI Score 17-25 & 0.009 & 0.11 & 0.907 & & & \\
\hline BDI Score>25 & 0.12 & 2.2 & $0.046 *$ & & & \\
\hline
\end{tabular}




\section{Discussion}

This study of adults with type- 2 diabetes demonstrates a significant relationship between depression weather measured as a continuous variable (BDI scores), or as a dichotomous variable (depressed/ not depressed according to DSM-IV), and glycemic control as measured by $\mathrm{HbA}_{1} \mathrm{c}$, the study shows that depressed diabetic patients have $\mathrm{HbA}_{1} \mathrm{c}$ levels significantly higher than their non depressed counterparts $(\mathrm{p}=0.01)$, and that there is significant correlation between BDI scores and $\mathrm{HbA}_{1} \mathrm{c}(\mathrm{r}=0.173, \mathrm{p}=0.021)$. The unadjusted observed relationship between depressive symptoms and glycemic control is linear throughout the complete range of observed BDI scores. This come in concordance with numerous cross sectional studies, ${ }^{14-17}$ as well as a meta-analysis of 30 studies found depression is associated with suboptimal glycemic control with moderate effect size. ${ }^{18}$

Although there many demographic, and clinical variables could influence glycemic control, the adjustment of this observed relationship for various demographic and clinical variables had weakened the relation but not eliminate it, after full adjustment only the major depressive disorder (MDD), and BDI scores higher than 25, but not the full range, were significant predictors for higher $\mathrm{HbAlc}$ $(\mathrm{p}=0.034$, and 0.046 respectively), which come in concordance with IDEA Tel study on elderly patients which found a significant correlation between depression and $\mathrm{HbAlc}$ at base line and a trend for depression to predict $\mathrm{HbA} 1 \mathrm{c}$ when other factors were controlled. ${ }^{7}$ this adjusted results stands between the studies who found positive relation between depression and glycemic control ${ }^{6,13}$ and those don't found such like relation, ${ }^{3,19}$ and as well goes consistent with the findings of the large meta-analysis ${ }^{18}$ which found that the association between depression and glycemic control was larger when standardized interviews and diagnostic criteria rather than self-report questionnaires were used to assess depression (ES 0.28 vs. 0.15 ). Perhaps because this relationship might be stronger in patients with clinical rather than subclinical depression. Self-report inventories are also less specific measures of depression, as elevated scores may be produced not only by depression but also by anxiety, general emotional distress, or medical illness. Like many other studies ${ }^{6-8,20}$ we have found patients with more depressive symptoms mostly females, less educated, with higher $\mathrm{FBG}, \mathrm{HbA}_{1} \mathrm{c}$, more disturbed metabolic profile, and more insulin users. however age, smoking, longer duration of diabetes, and diabetic related complications which have been found as risk factors for depression in diabetic patients, ${ }^{6}$ don't be confirmed through our findings.

It is worth mentioned to notice that prevalence of depressive disorders in this study reaches $16.3 \%$ for MDD, and 30\% for other depressive diagnoses (dysthymia, and mixed depression and anxiety disorder); many cross sectional studies located in Saudi Arabia found similar prevalence rates of depression among clinical samples of type2 diabetic patients., researchers who used BDI as screening tool found prevalence ranges $34 \%, 41.9 \%$, and $62.5 \%$ respectively, ${ }^{21-23}$ while those who used other screening tools found prevalence rates of $37.9 \%$, 45.8 , and $49.6 \%$ respectively. ${ }^{24-26}$ this finding goes in concordance with a large meta-analyses of prevalence of depression in adults with diabetes by Anderson et al. ${ }^{27}$ which included 42 studies that found prevalence of depression in clinical samples is $32.7 \%$, decreases by using structured interviews to $14.2 \%$, and increases by using selfreport instruments up to $34.9 \%$, and earlier study by Gavard et al. ${ }^{28}$ which found that major depression was present in $14.7 \%$, and elevated depression symptoms in $26 \%$ of diabetic patients.

The study has some limitations, first: clinical sample of depressed patients may not resemble general population sample due to changes in help seeking behavior. Second: is the cross sectional design of the study. And third: the influence of confounding factors cannot be fully accounted for. However the relation between depression and $\mathrm{HbA} 1 \mathrm{c}$ level is repeatedly found, it remains unclear if some other factors as changes in self care behavior, poor adherence to diabetes education programs, oral hypoglycemic medications and dietary interventions, or counter regulatory hormones ${ }^{3,29}$ mediate the relation between depression and glycemic control. Although this was not the focus of present study, it needs to be examined in future studies. The associations observed in this study are likely valid, however future studies need to validate our findings in different patient populations, and with prospective study design.

\section{Conclusion}

This study on adults with type 2 diabetes has demonstrated that sever depressive symptomatology, as well as major depressive disorder (MDD) are significantly associated with poorer glycemic control as measured by higher $\mathrm{HbA}_{1} \mathrm{c}$. We recommend to screen for depression among poorly controlled diabetic patients.

\section{Acknowledgements}

We thank all patients who agreed to share in this study, the Saudi airline medical center managers, and colleagues who help us in recruiting patients, data collection and patient assessment, Especially dr magdi maher (cardiology), Dr. Morad ali (ophthalmology), Dr. Riadh Mohamed (clinical pathology), and psychologist nada husein.

\section{Conflict of interest}

The author declares no conflict of interest.

\section{References}

1. Davydow DS, Russo JE, Ludman E, et al. The association of comorbid depression with intensive care unit admission in diabetes: A prospective cohort study. Psychosomatics. 2011;52(2):117-126.

2. Richardson Lk, Egede Le, Mueller M, et al. Longitudinal effect of depression on glycemic controle in veterans with type 2 diabetes. Gen Hosp Psychiatry. 2008;30(6):509-514.

3. Van Tilburg M, McCaskill C, Lane JD, et al. Depressed mood is a factor in glycemic control in type 1 diabetes. Psychosom Med. 2001;63(4):551-555.

4. Ali S, Stone M, Peters J, et al. The prevalence of co-morbid depression in adults with type 2 diabetes: a systematic review and meta-analyses. Diabet Med. 2006;23(11):1165-1173.

5. Barnard K, Skinner T, Peveler R. The prevalence of co-morbid depression I adults with type 1 diabetes: systematic literature review. Diabet Med. 2006;23(4):445-448.

6. Lloyd CE, Hermanns N, Nouwen A. The epidemiology of depression and diabetes. In: Katon W, Maj M, Sartorius N, editors. Depression and diabetes. Wiley-Blackwell, USA; 2010. p. 1-27.

7. Trief PM, Morin PC, Izquierdo R, et al. Depression and glycemic control in elderly ethnically diverse patients with diabetes. The IDEATel Project. Diabetes Care. 2006;29(4):830-835.

8. Katon W, Von Korff M, Ciechanowski P, et al. Behavioural and clinical factors associated with depression among individuals with diabetes. Diabetes care. 2004;27(4):914-920.

9. Beck AT, Ward CH, Mendelson M, et al. An inventory for measuring depression. Arch Gen Psychiatry. 1961;4:561-571. 
10. Leedom L, Meehan WP, Procci W, et al. Symptoms of depression in patients with diabetes mellitus. Psychosomatics. 1991;32(3):280-286.

11. Lustman PJ, Clouse RE, Griffith LS, et al. Screening for depression in diabetes using the Beck Depression Inventory. Psychosom Med. 1997;59(1):24-31.

12. Wing RR, Marcus MD, Blair EH, et al. Depressive symptomatology in obese adults with Type II diabetes. Diabetes Care. 1990;13(2):170172.

13. Abdel-khalek AM. Internal consistency of an Arabic adaptation of the beck depression inventory in four Arab countries. Psychol Rep. 1998;82(1):264-266.

14. Niemcryk SJ, Speers MA, Travis LB, et al. Psychosocial correlates of hemoglobin $\mathrm{A}_{1} \mathrm{c}$ in young adults with type 1 diabetes. $J$ Psychosom Res. 1990;34(6):617-627.

15. Karlsson JA, Holmes CS, Lang R. Psychosocial aspects of disease duration and control in young adults with type 1 diabetes. J Clin Epidemiol. 1988;41(5):435-440.

16. Von Dras D, Lichty W. Correlates of depression in diabetic adults. Behav Health Aging. 1990;1:79-84.

17. Lee PWH, Lam KSL, Lieh-Mak F, et al. Emotional maladjustment, physical malaise and diabetic control in young Chinese patients with diabetes. Psych Health Med. 1996;1(1):119-127.

18. Lustman PJ, Anderson RJ, Freedland KE, et al. Depression and poor glycemic control. Diabetes care. 2000;23(7):934-942.

19. Ciechanowski PS, Katon WJ, Russo JE. Depression and Diabetes Impact of Depressive Symptoms on Adherence, Function, and Costs. Arch Intern Med. 2000;160(21):3278-3285.

20. Ganasegeran K, Renganathan P, Abdul Manaf R, et al. Factors associated with anxiety and depression among type 2 diabetes outpatients in Malaysia: A descriptive cross-sectional single-centre study. BMJ Open. 2014;4(4):004794e.
21. Al-Ghamdi AA. A high prevalence of depression among diabetic patients at a teaching hospital in Western Saudi Arabia. Neurosciences (Riyadh). 2004;9(2):108-112.

22. Trabulsi FA, Almasaodi KA. Depression among type 2 diabetic patients in Al-Eskan Avenue in Makkah, 2010. American Journal of Research Communication. 2013;1(10):49-68.

23. Saadalla AM, Mirghani HO, Mohammed OS, et al. Depression and type 2 diabetes mellitus: A case-control study in Tabuk, Saudi Arabia. Basic Research Journal of Medicine and Clinical Sciences. 2015;4(11):248-252.

24. Gemeay EM, Moawed SA, Mansour EA, et al. The association between diabetes and depression. Saudi Med J. 2015;36(10):1210-1215.

25. AL-Baik MZ, Moharram M, Elsaid T, et al. Screening for depression in diabetic Patients. Int J Med Sci Public Health. 2014;3(2):156-160.

26. El Mahalli AA. Prevalence and Predictors of Depression among Type 2 Diabetes Mellitus Outpatients in Eastern Province, Saudi Arabia. Int J Health Sci (Qassim). 2015;9(2):119-126.

27. Anderson RJ, Freedland KE, Clouse RE, et al. The prevalence of comorbid depression in adults with diabetes: A meta-analysis. Diabetes Care. 2001;24(6):1069-1078.

28. Gavard JA, Lustman PJ, Clouse RE. Prevalence of depression in adults with diabetes: an epidemiological evaluation. Diabetes Care. 1993;16(8):1167-1178.

29. Staab J, Evans D, Musselman D. Depression and diabetes. In: Evans $\mathrm{D}$, Charney D, Lewis L, Editors. The physicians guide to depression and bipolar disorders. USA: McGraw-Hill; 2006. p. 157-168. 